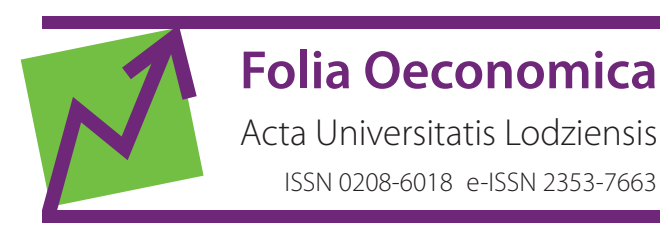

www.czasopisma.uni.lodz.pl/foe/

4(343) 2019

DOI: http://dx.doi.org/10.18778/0208-6018.343.06

\author{
Anna Lucyna Wziątek-Staśko \\ Uniwersytet Jagielloński, Wydział Zarządzania i Komunikacji Społecznej \\ Katedra Zarządzania Zasobami Ludzkimi, anna.wziatek-stasko@uj.edu.pl
}

\title{
Różnorodność pokoleniowa pracowników a preferowany model kultury organizacyjnej
}

Streszczenie: Zbieżność wartości kluczowych dla organizacji z wartościami istotnymi dla pracowników stanowi problem badawczy o priorytetowym znaczeniu dla współczesnych przedsiębiorców oraz jedno z kluczowych wyzwań, któremu powinni oni poświęcić szczególną uwagę. Przedmiotem rozważań podjętych w niniejszym artykule jest kultura organizacyjna i jej postrzeganie przez pracowników w różnym wieku. Coraz bardziej widoczna stereotypizacja cech oraz preferencji przedstawicieli różnych pokoleń, dotyczących ich funkcjonowania w środowisku pracy, stała się inspiracją do podjęcia autorskich badań w przedmiotowym zakresie. W badaniach uczestniczyło 664 polskich respondentów. W procesie badawczym wykorzystano metody ilościowe. Celem artykułu jest prezentacja obecnego oraz pożądanego modelu kultury organizacyjnej w ocenie pracowników w różnym wieku.

Słowa kluczowe: kultura organizacyjna, model, wiek, pokolenie

JEL: M12, M54, M55 


\section{Wprowadzenie}

Choć kultura organizacyjna jako kategoria badawcza jest bardzo popularna w świecie nauki, wciąż wydaje się dość powierzchownie traktowana przez kadry menedżerskie przedsiębiorstw oraz ich pracowników. Wydaje się pojęciem niedostatecznie zrozumianym i eksplorowanym w sposób dość intuicyjny. Być może dzieje się tak dlatego, że operacjonalizacja pojęcia w istocie nie należy do łatwych, aczkolwiek jest ważna i implikuje określone konsekwencje. „Kultura organizacji jest nośnikiem określonych norm i wartości preferowanych w zachowaniu kierownika i podwładnych. Oznacza to, że istnieje zależność między skutecznością kierowania a zdolnością kierujących do rozpoznawania właściwego, obowiązującego w danej organizacji, systemu wartości, normami zachowań a systemem wartości oraz zasadami i sposobami postępowania i myślenia, którymi kierują się podwładni. Posiadanie tej umiejętności przez kierowników sprzyja doborowi odpowiednich metod i technik oddziaływania na podwładnych, które pozwalają osiągnąć zamierzone cele" (Serafin, 2015: 96). Niestety, autorka w swojej wypowiedzi nie precyzuje, o czyje cele chodzi, a to kwestia istotna. Eksponowanie celów i wartości ważnych wyłącznie dla organizacji oraz kadr menedżerskich, z pominięciem tych, które są istotne dla pracowników zatrudnionych na pozostałych stanowiskach, może być bowiem dla organizacji niebezpieczne. W opinii D. Kokt i R. Ramarumo (2014: 1199) „kadry menadżerskie odgrywają ogromnie istotną rolę w procesie zrozumienia, kreacji oraz zarządzania kulturą organizacyjną". Ważne więc, by przedsiębiorcy dysponowali aktualną wiedzą na temat wartości kluczowych dla swoich pracowników, a także, by wartości te były zbieżne z ich wartościami.

Głównym celem niniejszego artykułu jest prezentacja autorskich wyników badań poświęconych identyfikacji wartości kluczowych dla pracowników różnych szczebli, według stanu obecnego oraz przez nich pożądanego. Kryterium różnicującym opinie respondentów uczyniono wiek pracowników. Intencją autorki było bowiem udzielenie odpowiedzi na pytanie, czy przynależność pokoleniowa pracownika determinuje jego preferencje dotyczące pożądanego przez niego modelu kultury organizacyjnej. Różnorodność pokoleniowa pracowników i jej wpływ na kształt procesu zarządzania to problem szeroko poruszany przez współczesnych badaczy. Dotychczas prezentowane dywagacje naukowe, związane z multigeneracyjnością, dotyczą wielu różnych obszarów badawczych (np. rekrutacji i selekcji, motywowania, oceny pracowników), nie obejmują jednak kultury organizacyjnej. Zidentyfikowaną zależność o istotnych walorach praktycznych należy więc potraktować jako lukę badawczą. 


\section{Kultura organizacyjna - nieoczywista próba operacjonalizacji pojęcia}

Dokonując próby wyjaśnienia, czym jest w istocie kultura organizacyjna, należy zachować dużą pokorę. Wieloaspektowość pojęcia sprawia, że próba jego operacjonalizacji jest niezmiernie trudna i stanowi duże wyzwanie dla badaczy, którzy poświęcają jej uwagę od ponad stu lat (Connolly, Lang, Gathegi, Tygar, 2017: 122). W tym czasie zidentyfikowano około czterystu definicji pojęcia (Kovačić, 2005: 143-158) i proces ten zdaje się nie mieć końca. Skomplikowany charakter kultury organizacyjnej potwierdza wielu autorów z całego świata (np. Yiing, Ahmad, Bin, 2009: 53-89; Altaf, 2011: 161-162; Neagu, Nicula, 2012: 420-424; Sokro, 2012: 106-119; Su, Yang, Yang, 2012: 5317-5329; Gimenez-Espin, Jiménez-Jiménez, Martínez-Costa, 2013: 678-692; Weare, Lichterman, Esparza, 2014: 590-619; Harrington, Voehl, 2015: 56; Saad, Asaad, 2015: 379-394). Badacze kultury organizacyjnej utożsamiają ją z osobowością organizacji, filozofią, która kieruje polityką organizacji, rdzeniem wartości, które określają filozofię lub misję firmy, zwyczajowymi i tradycyjnymi sposobami myślenia i działania, klimatem organizacyjnym, symbolami, językiem, ideologiami, rytuałami, mitami, wartościami, normami, wiedzą, wzorami procesów myślowych, mową lub żargonem (Zbiegień-Maciąg, 1999: 17; Srokowski, 2011: 26; Wudarzewski, 2013: 59-78; La Montagne, 2016: 9). Powyższe określenia wskazują, czym jest kultura organizacyjna. Niektórzy wyjaśniają również, czym ona nie jest: „Kultura organizacyjna to nie ekskluzywne wyposażenie, piękne obrazy w biurach, to nie organizowanie wyjazdów na grzyby, wieczorków poetyckich. Są to możliwe części kultury organizacyjnej, ale to wcale nie oznacza, że kultura organizacyjna musi takie elementy posiadać" (Markiewicz, 2005: 44). O ile bardzo problematyczne wydaje się zaproponowanie uniwersalnej definicji kultury organizacyjnej, o tyle dość łatwo przychodzi wskazanie jej związków z innymi wyróżnikami funkcjonowania organizacji. „Zasady postępowania, normy i wartości wynikające z kultury organizacyjnej determinują zarówno efektywność formułowanej strategii przedsiębiorstwa, skuteczność procesów zarządzania zmianą, jak również skuteczność systemów motywacyjnych" (Altaf, 2011: 161-162; zob. też: Hulkko-Nyman, Sarti, Hakonen, Sweins, 2014: 24-49; Jacobs, Renard, Snelgar, 2014: 1-13; Harrington, Voehl, 2015: 56; Aybas, Cevat Acar, 2017: 363-372; Yongxing, Hongfei, Baoguo, Lei, 2017: 708-713). Potwierdzają to również inni autorzy: „Istnieje sprzężenie zwrotne między sposobem motywowania w organizacji a jej kulturą. Z jednej strony kultura organizacyjna wraz ze swymi wartościami i normami stanowi wyznacznik motywowania (motywuje zgodnie z tym, w co wierzę, i z tym, co jest dla mnie ważne). Z drugiej strony, motywowanie powiązane z procedurami polityki personalnej, sposobem sprawowania władzy i komunikacji w firmie pozwala pracownikom zrozumieć i zaakceptować 
normy i wartości kultury" (Aniszewska, 2007: 142). Na komplementarność kultury organizacyjnej oraz instrumentów zarządzania zasobami ludzkimi zwracają uwagę także J.K. Rodrigues i P. Steward (2017: 378-390). Kultura organizacyjna kształtuje motywy zachowań organizacyjnych. „Odpowiednio silna kultura może dobrze stymulować pracowników do kreatywności i innowacyjności, może także zachęcać ich do podejmowania ryzyka" (Saad, Asaad, 2015: 380; zob. też: Pakdil, Leonard, 2014: 725-744; Laforet, 2015: 379-407; Connolly, Lang, Gathegi, Tygar, 2017: 118-136; Douglas, Muturi, Douglas, Ochieng, 2017: 666-676). Kultura organizacyjna to również czynnik determinujący poziom zaangażowania pracowników (Wziątek-Staśko, 2018: 409-419). Pracownicy, którzy podzielają preferowane przez daną kulturę wartości i normy zachowań oraz sposoby postępowania i myślenia, będą w większym stopniu identyfikowali się z przedsiębiorstwem, w którym pracują, będą bardziej zaangażowani w rozwiązywanie jego problemów (Tolentino, 2013: 5). Wysoko zaangażowane środowisko pracy poprawia wskaźnik retencji pracowników, obniża koszty operacyjne oraz przyczynia się do wzrostu wydajności i wyników pracowników. Zaangażowanie organizacyjne wpływa na wzrost poziomu motywacji pracowników, satysfakcji z pracy, wzmacnia ich morale i podnosi poziom dobrego samopoczucia (Rich, Lepine, Crawford, 2010: 617-635; Tepeci, 2011: 19-35; Hoole, Bonnema, 2015: 1-11; Victor, Hoole, 2017 : 1-14; Wziątek-Staśko, Krawczyk-Antoniuk, 2017: 185-193). Istniejący w organizacji model kultury organizacyjnej może więc w istotny sposób wspomagać efektywność zarządzania nią i pracownikami, ale może także skutecznie ją zaburzać (Eaton, Kilby, 2015: 1-4; Harrington, Voehl, 2015: 56; La Montagne, 2016: 9).

Większość badaczy pozytywnie postrzega kulturę organizacyjną, eksponując jej liczne atuty. Istnieją również i tacy, którzy dostrzegają jej słabości. Zdaniem niektórych autorów kultura organizacyjna jest czynnikiem determinującym występowanie różnych dysfunkcji, a nawet patologii w procesie zarządzania: „kultura organizacyjna to jedno z głównych źródeł patologii zachowań społecznych" (Tarnowska, 2011: 74). Powyższy pogląd potwierdza także inna autorka, konstatując, iż ,patologia organizacyjna to ekstremalna forma dysfunkcji organizacyjnej, a dysfunkcja to niewypełniona bądź błędnie wypełniona funkcja kultury organizacyjnej" (Pietruszka-Ortyl, 2016: 441). Również A. Wziątek-Staśko (2017: 27-34) zwraca uwagę na szczególnie patologiczny charakter niektórych modeli kultur organizacyjnych. Nie bez znaczenia pozostają także opinie sugerujące, iż kultura organizacyjna może stanowić dla pracowników źródło stresu oraz wypalenia zawodowego (Kokt, Ramarumo, 2014: 1198-1213) czy też istotny czynnik determinujący występowanie zachowań kontrproduktywnych w organizacji (Zheng, Wu, Chen, Lin, 2017: 563-578).

Niektórzy badacze prezentują dość intrygujący pogląd na temat kultury organizacyjnej, eksponując jej negatywny charakter oraz nazywając „narzędziem dominacji i opresji, hipostazą i ideologią, wątkiem pseudonaukowym i modą, czy wręcz psychicznym więzieniem" (Sułkowski, 2011: 8). Cytowany autor formułuje 
również pogląd, iż: „Krytyczny ogląd kultur organizacyjnych prowadzi do wniosku, że poprzez przemoc symboliczną stanowią one kluczowy mechanizm podtrzymywania i reprodukcji nierówności" (Sułkowski, 2011: 16). Zwraca on także uwagę na konieczność „diagnozy opresyjności kultury organizacyjnej, rozpoznania i ujawnienia ideologicznej funkcji oraz tworzenia fałszywej świadomości w obrębie procesów kulturowych współczesnej organizacji, ujawnienia mechanizmów i skali »przemocy symbolicznej« w organizacjach, opisania instrumentalnych, manipulacyjnych i socjotechnicznych metod »kulturyzmu« w organizacjach, przedstawienia wizji kulturowych mechanizmów kontrolnych, zbliżających organizacje do typu idealnego »instytucji totalnych «, odkrycia »neokolonialnych « koncepcji i praktyk międzynarodowych korporacji kryjących się pod zasłoną zarządzania międzykulturowego i procesów globalizacyjnych, przedstawienia mechanizmów »kolonizacji umysłów«, tworzenia »człowieka jednowymiarowego« kontrolowanego przez kulturę konsumpcjonizmu, analizy całego dorobku zarządzania jako projekcji kultury legitymizującej władzę i podtrzymującej status quo, krytyki kultury kształcenia menedżerskiego, biznesowego i ekonomicznego na świecie, odkrycia roli guru w procesie kamuflowania struktur władzy" (Sułkowski, 2011: 9). Opinię o podobnym charakterze wyraża także inny autor, twierdząc, iż: „Znaczna większość opisów kultury organizacyjnej, czyli opisów analiz następujących po zdefiniowaniu pojęcia »kultura organizacyjna«, jest zamykaniem organizacji i tworzących je ludzi w kulturowych kapsułach, czego etycznymi i metodologicznymi efektami jest wzmacnianie hegemonii dyskursu dominującego oraz spójna wizja całości kosztem utraty zrozumienia złożoności” (Krzyworzeka, 2012: 76).

Próba dokonania syntetycznego spojrzenia na istotę kultury organizacyjnej wydaje się niezmiernie skomplikowana. Powszechne utożsamianie jej z wartościami, normami, artefaktami (co najczęściej znajduje odzwierciedlenie na kartach literatury tematu) jest nader dużym uproszczeniem, mogącym zmieniać kształt oraz głębię prowadzonych dywagacji naukowych. Coraz częściej pojawiające się opinie, iż kultura organizacyjna może stanowić poważne źródło różnego typu dysfunkcji oraz patologii organizacyjnych, a także czynnik destrukcyjnie oddziałujący na skuteczność procesu zarządzania o charakterze manipulacyjnym, inspirują do spojrzenia na kulturę z nieco innej strony, niż czyniono to w większości przypadków. Nie będzie to jednak przedmiotem dociekań podjętych w niniejszym artykule.

\section{Różnorodność pokoleniowa - w kręgu wątpliwości}

Różnice pokoleń, różnorodność pokoleniowa, różnice międzypokoleniowe, generacja, multigeneracyjność, zarządzanie wiekiem, ageizm to tylko niektóre określenia wskazujące na dużą wagę przypisywaną pokoleniom pracowników i ich sugerowanej odmienności. Autorzy publikacji na całym świecie w dość swobod- 
ny sposób dokonują kategoryzacji pracowników, wziąwszy pod uwagę ich wiek. Pojawiają się wciąż nowe nazwy pokoleń oraz odmienne zakresy dat ich urodzenia (Levickaite, 2010: 170-183; Costanza, Badger, Fraser, Severt, Gade, 2012: 375-394; Smolbik-Jęczmień, 2013: 228-238; Sarraf, Abzari, Isfahani, Fathi, 2017: 106-115). Różnorodność nazw pokoleń jest duża: The Greatest Generation, The Silent Generation, The Baby Boom Generation, Generation X or Baby Busters, Generation Y, Echo Boomers or MTV Generation, Millennials, Generation Next or Net Generation, Peter Pan Generation, Gen Xer, Generation I, The Internet Generation or Generation Next, Net Generation or iGeneration, The New Silent Generation, Radio Babies, Yummies, Multitasking Generation, pokolenie płatków śniegu i inne. Różnorodność nazw to także różnorodność cech przypisywanych przedstawicielom poszczególnych pokoleń, skutecznie sprzyjająca stereotypizacji (Wziątek-Staśko, 2015: 47-60). „Wczytując się w niektóre opisy poszczególnych pokoleń, zastanowić się można, czy i na ile tego typu charakterystyki mogłyby pasować do członków teoretycznie »innych« pokoleń, a może nawet po prostu do każdego człowieka? Przykładowo o »przeciętnym przedstawicielu« jednego z pokoleń można przeczytać, że pragnie pracy, która będzie mu sprawiała przyjemność - a czy pod takim stwierdzeniem nie podpisałoby się wielu pracowników, zwłaszcza gdybyśmy o to zapytali w poniedziałkowy poranek? [...] Na postrzeganie ewentualnych różnic między pracownikami przez samych pracowników, ale także przez opinię publiczną mają wpływ przyjęte w mediach narracje. Czym innym zatem są próby systematyzacji i zwracanie uwagi na określone tendencje, którym podlegają kolejne grupy wchodzące na rynek pracy, a czym innym - pojawiające się uproszczenia" (Brol, 2016: 42).

Termin pokolenie bywa rozmaicie definiowany. Wyróżnić można cztery podejścia wykorzystywane w naukach społecznych (Szukalski, 2012: 12). Zgodnie z pierwszym z nich pokoleniem nazywa się „ogół spokrewnionych jednostek, posiadających wspólnego przodka o tym samym dla wszystkich statusie rodzinnym" (Szukalski, 2012: 12). Drugie podejście, typowe dla polityki społecznej, definiując pokolenie, uwzględnia przede wszystkim (potencjalną) aktywność zawodową, wyodrębniając osoby w wieku przedprodukcyjnym, produkcyjnym i poprodukcyjnym (Szukalski, 2012: 13). Trzecie podejście „ujmuje pokolenie jako grupę osób $\mathrm{w}$ zbliżonym wieku, tj. urodzonych w tym samym okresie, $\mathrm{z}$ reguły analizowanym z punktu widzenia roku lub lat pięciu" (Szukalski, 2012: 13). Odmienne jest czwarte podejście, odwołujące się „do podobieństwa kulturowego, wynikającego z wpływu traumatycznego doświadczenia, które odcisnęło swe piętno w sposobie myślenia w grupie osób rozpoczynających dorosłość, determinując przebieg ich życia i sposób definiowania rzeczywistości, będący wyzwaniem dla sposobu dotąd rozpowszechnionego" (Szukalski, 2012: 13). Dywersyfikacja pokoleń i cech im przypisywanych stała się przedmiotem licznych badań dotyczących wpływu wieku pracownika i związanej z tym przynależności generacyjnej na poziom zaan- 
gażowania oraz satysfakcji z pracy (Shragay, Tziner, 2011: 143-157; Waal, Peters, Broekhuizen, 2016: 86-101; Cucina, Byle, Martin, Peyton, Gast, 2017: 878-890), na poziom motywacji do pracy (Westerman, Yamamura, 2006: 150-161; Wong, Gardiner, Lang, Coulon, 2008: 878-890), na metodykę kreacji i zarządzania konfliktem (Bennett, Beehr, Ivanitskaya, 2017: 314-332), na sposób postrzegania pracodawcy (Guillot-Soulez, Soulez, 2014: 319-332). Ich wyniki nie są jednoznaczne i wiążą się z wieloma ograniczeniami: „Charakteryzując różne pokolenia w miejscu pracy, warto stale zadawać pytanie, czy dane pokolenie takie jest, czy raczej niektórzy jego przedstawiciele zachowują się w taki sposób, by odnaleźć się w sytuacji? Wydaje się, że w pierwszym przypadku istnieje większe ryzyko, by pomijać różnice indywidualne pomiędzy poszczególnymi pracownikami, przypisując ten sam zestaw cech wszystkim »członkom« danego pokolenia. Chociaż propozycje nazw i opisów pokoleń mają porządkować otaczającą rzeczywistość rynku pracy, to jednocześnie może to budować i utrwalać mity, zwłaszcza na temat młodych ludzi rozpoczynających pracę" (Brol, 2016: 47). Warto zauważyć, iż idea multigeneracyjności w wyraźny sposób wydaje się przeczyć założeniom koncepcji zarządzania różnorodnością, eksponującej wyjątkowość każdej istoty ludzkiej, mającej właściwe tylko sobie cechy, marzenia, oczekiwania, plany, wartości, wymagającej zastosowania zindywidualizowanych narzędzi zarządzania (Wziątek-Staśko, 2012). Niezależnie od wyrażonych powyżej wątpliwości dotyczących powszechnie stosowanych prób „szufladkowania” współczesnych pracowników interesujące pozostaje to, jakie wartości są kluczowe dla pracowników w różnym wieku i jaki w związku z tym preferują model kultury organizacyjnej w swoim miejscu pracy. Czy wiek stanowi w tym zakresie kategorię różnicującą?

\section{Metodyka badań}

Głównym celem autorskich badań empirycznych było poszukiwanie odpowiedzi na następujące pytania badawcze:

1. Jaki model kultury organizacyjnej występuje aktualnie w badanych przedsiębiorstwach?

2. Jaki model kultury organizacyjnej pracownicy wskazują jako idealny/ pożądany?

3. Czy istnieje zbieżność, czy rozbieżność w ocenie preferencji respondentów dotyczących istniejącego oraz pożądanego przez nich modelu kultury organizacyjnej?

4. Czy zależność między modelem kultury organizacyjnej, deklarowanym jako pożądany przez respondentów, a ich wiekiem jest istotna statystycznie?

5. Jak kształtują się preferencje badanych w poszczególnych grupach wiekowych, dotyczące pożądanego przez nich modelu kultury organizacyjnej? 
W procesie badawczym do oceny kultury organizacyjnej wykorzystano kwestionariusz OCAI (Organisational Culture Assessment Instrument) autorstwa K. S. Camerona i R.E. Quinna (2003: 28). Składa się on z sześciu części, każda z nich jest poświęcona odpowiedzi na jedno pytanie dotyczące przedsiębiorstwa zatrudniającego respondenta. W pytaniach 1-6 podano cztery warianty odpowiedzi (A, B, C i D), między które należało rozdzielić sto punktów, w zależności od tego, w jakim stopniu dana odpowiedź odzwierciedlała sytuację w organizacji. Najwięcej punktów należało przypisać odpowiedzi, która jest najbliższa sytuacji istniejącej w organizacji, a najmniej tej, która najbardziej od niej odbiega. Każda z odpowiedzi reprezentowała cechy konkretnej kultury. Następnie na potrzeby dalszej analizy statystycznej obliczono średnie uzyskane w poszczególnych ankietach według metodologii Camerona i Quinna. Posłużyło to do określenia dominującego modelu (obecnego i pożądanego) dla każdej z ankiet. Wynikiem ostatecznym dla każdej z ankiet były dwie wartości: wartość modelu obecnie funkcjonującego w organizacji (A, B, C lub D) i analogicznie wartość modelu pożądanego.

Badanie statystycznie istotnych różnic między zmiennymi przeprowadzono za pomocą testu Chi-kwadrat $\left(\chi^{2}\right)$ niezależności Pearsona. Do badań przyjęto poziom istotności statystycznej $\alpha=0,05$. Anonimowe badania, na losowo wybranej próbie respondentów, przeprowadzono z wykorzystaniem papierowej wersji narzędzia badawczego. Uczestnikami badań byli studenci studiów niestacjonarnych uczelni ekonomicznych z siedzibą w województwie śląskim. Respondentom rozdano łącznie 700 kwestionariuszy, a do ostatecznej analizy zakwalifikowano 664 kompletne i poprawnie wypełnione formularze. W procesie badawczym uczestniczyło 347 kobiet $(52,2 \%)$ oraz 317 mężczyzn (47,8\%), reprezentujących różne kategorie wiekowe: $18-25$ lat $(N=337 ; 50,8 \%), 26-35$ lat $(N=170 ; 25,6 \%), 36-45$ lat $(N=124 ; 18,7 \%), 46-55$ lat $(N=30 ; 4,5 \%)$, powyżej 55 lat $(N=3 ; 0,5 \%)^{1}$. Z uwagi na brak jednolitej, powszechnie obowiązującej

1 Struktura wykształcenia badanych osób kształtowała się następująco: wykształcenie podstawowe $0,2 \%(N=1)$, wykształcenie zawodowe $0,9 \%(N=6)$, wykształcenie średnie $79,8 \%$ $(N=530)$, wykształcenie wyższe $19 \%(N=126)$, osoby posiadające stopnie lub tytuły naukowe $0,2 \%(N=1)$. Spośród ogółu respondentów na stanowisku robotniczym było zatrudnionych $37 \%$ osób $(N=246)$, na stanowisku nierobotniczym bez podległych pracowników $44,6 \%(N=296)$, na stanowisku menedżera najniższego szczebla $4,7 \%(N=31)$, menedżera średniego szczebla 10,7\% $(N=71)$, menedżera najwyższego szczebla $3 \%(N=20)$. Uczestnicy badań to osoby o różnym stażu pracy ogółem: poniżej 5 lat 49,4\% $(N=328)$, w przedziale $5-15$ lat $30,4 \%(N=202)$, powyżej 15 lat $20,2 \%(N=134)$. Osoby o stażu pracy w obecnej firmie poniżej 5 lat stanowiły $70,3 \%(N=467)$, w wymiarze $5-15$ lat $19,6 \%(N=130)$, powyżej 15 lat $10,1 \%(N=67)$. Osoby o stażu pracy na obecnym stanowisku pracy poniżej 5 lat to $75,4 \%(N=500)$, w wymiarze $5-15$ lat $19,9 \%(N=132)$, powyżej 15 lat $4,7 \%$ $(N=32)$. Respondenci reprezentowali różnego typu organizacje: sektor prywatny $79,2 \%$ $(N=525)$, państwowy 17,6\% $(N=117)$, trzeci sektor 3,2\% $(N=21)$, różnej wielkości mikroprzedsiębiorstwa $15 \%(N=99)$, przedsiębiorstwa małe $19,2 \%(N=127)$, średnie $23 \%$ 
klasyfikacji grup pokoleniowych oraz granicznych kategorii wiekowych w procesie badawczym nie posłużono się nazewnictwem generacji prezentowanym w literaturze przedmiotu.

Modelem kultury organizacyjnej, który posłużył do badań dla potrzeb niniejszego artykułu, był model wartości konkurujących (ang. Competing Values Framework) autorstwa K.S. Camerona oraz R. E. Quinna. Typologia modeli kultur wyżej wymienionych autorów obejmuje: kulturę klanu - A, adhokracji - B, rynku - C oraz hierarchii - D. Ich wybrane cechy zaprezentowano na Rysunku 1.

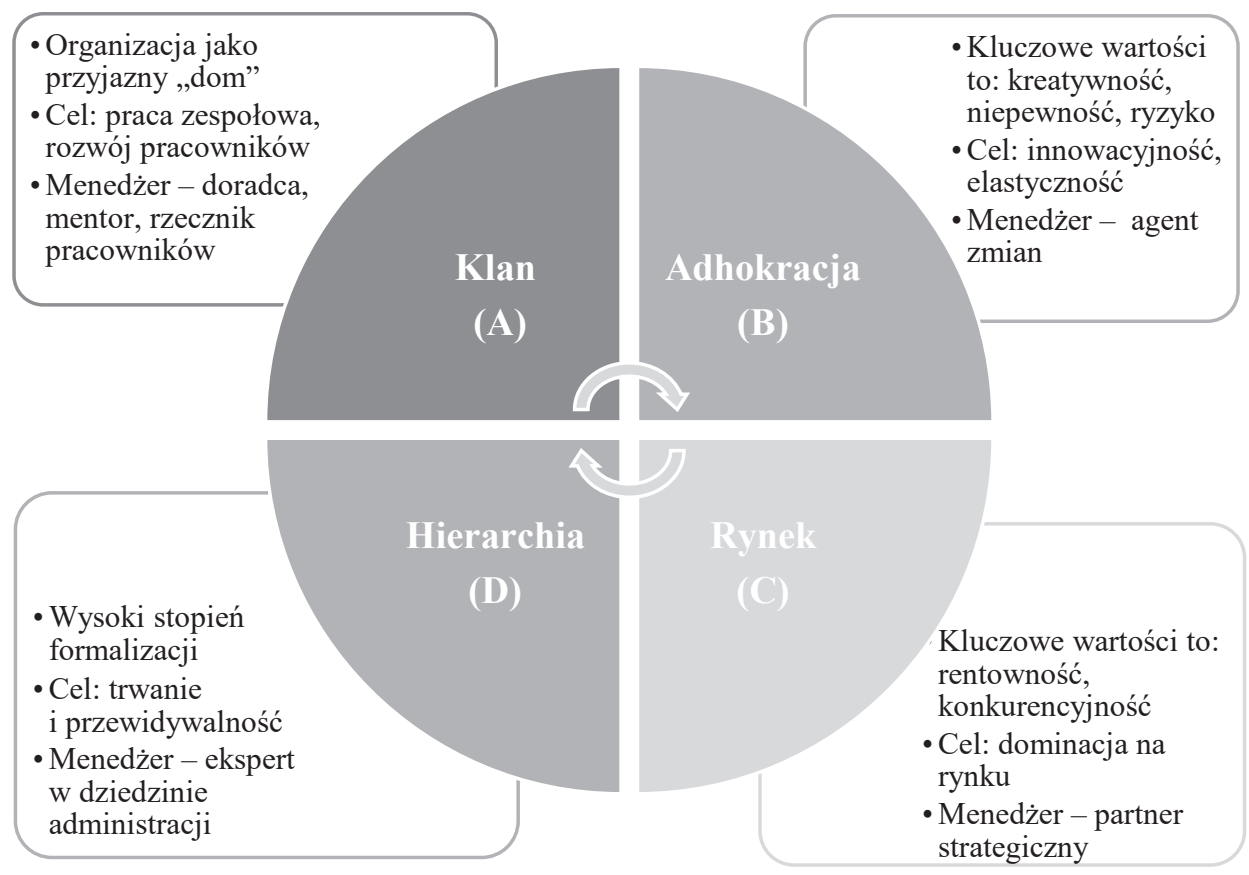

Rysunek 1. Model wartości konkurujących K.S. Camerona i R.E. Quinna

Źródło: opracowanie własne na podstawie: Cameron, Quinn, 2003: 40

$(N=152)$ oraz duże $42,7 \%(N=282)$. Jeden respondent nie zadeklarował przynależności do organizacji o określonej formie własności, a czterech do organizacji o danej wielkości, dlatego też w obu przypadkach suma nie wynosi 664. Powyższy fakt nie wpłynął na wyłączenie kwestionariuszy $\mathrm{z}$ dalszej analizy $\mathrm{z}$ uwagi na drugorzędne znaczenie pominiętych kategorii w procesie badawczym. 


\section{Prezentacja oraz omówienie wyników badań empirycznych}

Istotną częścią badań empirycznych była diagnoza typu modelu kultury organizacyjnej aktualnie występującego w badanych organizacjach oraz modelu pożądanego przez pracowników w ujęciu ogólnym. Opinie respondentów dotyczące powyższych kwestii zaprezentowano na Rysunku 2.

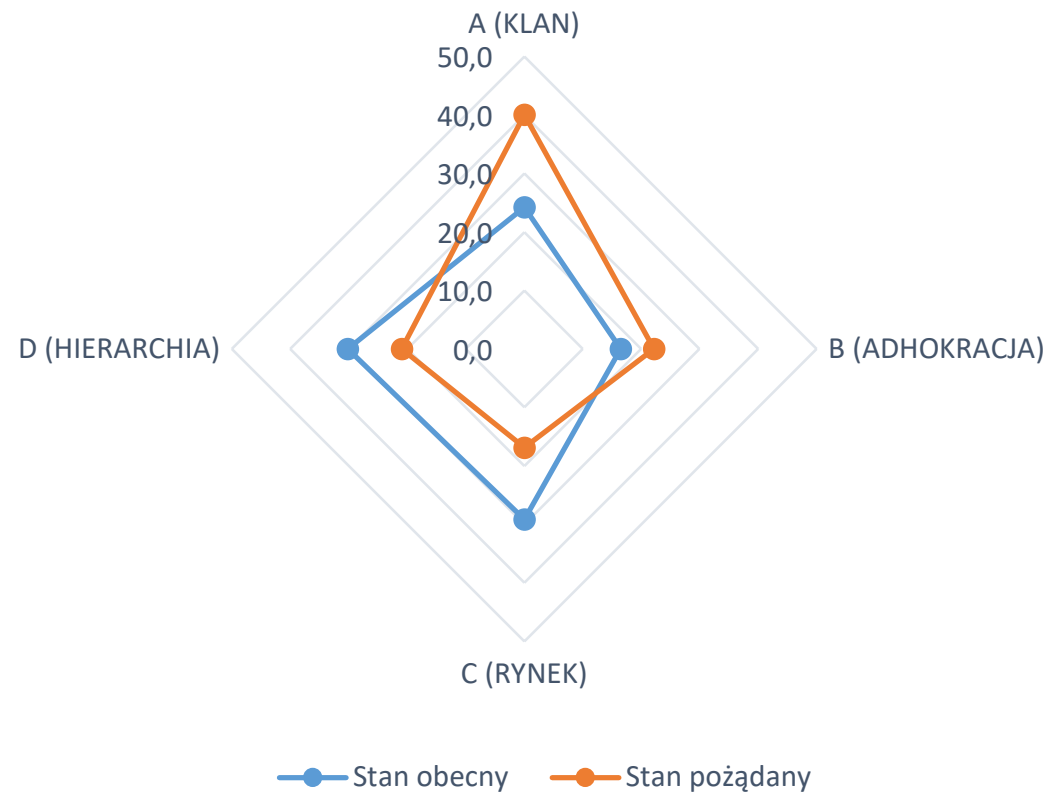

Rysunek 2. Obecny oraz pożądany model kultury organizacyjnej w opinii badanych respondentów Źródło: opracowanie własne

Z danych zaprezentowanych na Rysunku 2 wynika, iż dominującymi modelami kultury organizacyjnej, wskazanymi jako modele obecnie istniejące, są: kultura hierarchii (30,2\% wskazań) oraz kultura rynku (29,1\%). Modelem najbardziej pożądanym przez respondentów okazał się model kultury klanu (40,1\%), a najmniej pożądanym model kultury rynku (16,8\%). Model obecny wyraźnie odbiega więc od modelu pożądanego. Rozbieżność opinii badanych jest dość znacząca, zwłaszcza w odniesieniu do typu modelu przez nich pożądanego. Jeden z modeli wskazanych jako aktualnie najczęściej występujący - kultura rynku - jest też jednocześnie modelem wskazanym jako najmniej pożądany. To wynik obrazujący istotny problem organizacyjny. Wartości charakterystyczne dla organizacji nie są zgodne z tymi, które są kluczowe dla pracowników. Pracownicy zdają się bardziej doceniać środowisko pracy, którego dominującą cechą jest życzliwość, otwartość i wsparcie 
we wzajemnych relacjach, niż biurokrację i nieustanne eksponowanie znaczenia osiąganych wyników kosztem większej troski o pracownika i jego potrzeby.

W trakcie badań poszukiwano odpowiedzi na dwa istotne pytania:

1. Czy zależność między modelem kultury organizacyjnej, deklarowanym jako pożądany przez respondentów, a ich wiekiem jest istotna statystycznie?

2. Jak kształtują się preferencje badanych w poszczególnych grupach wiekowych, dotyczące pożądanego przez nich modelu kultury organizacyjnej?

Analiza zebranego materiału faktograficznego wykazała, iż zależność występująca między poddanymi ocenie kategoriami - ,pożądanym modelem kultury organizacyjnej” i ,wiekiem pracowników” - nie jest istotna statystycznie $\left(p=0.09814^{* * *}, p>\alpha\right)$, co oznacza, że preferencje pracowników dotyczące pożądanego przez nich modelu kultury organizacyjnej nie są zależne od wieku. Szczegóły uwidoczniono na Rysunku 3.

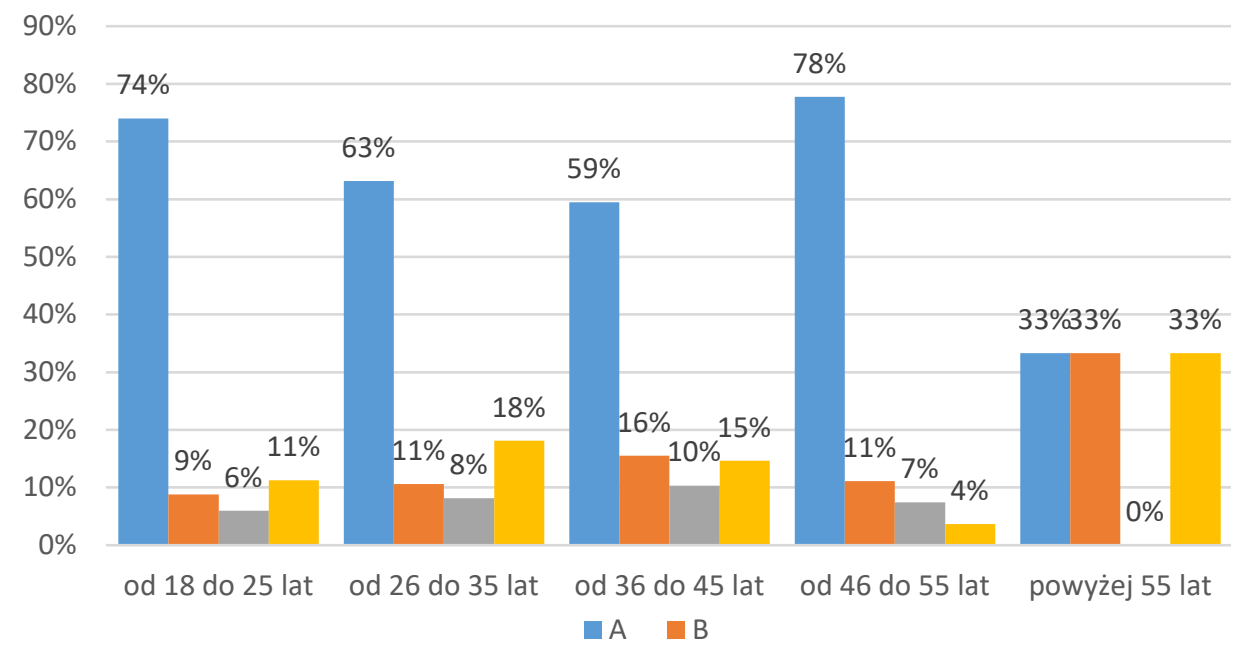

Rysunek 3. Wiek pracowników a pożądany model kultury organizacyjnej

Źródło: opracowanie własne

Z danych przedstawionych na Rysunku 3 wynika, iż modelem kultury organizacyjnej zdecydowanie najczęściej wskazywanym przez pracowników reprezentujących wszystkie grupy wiekowe okazała się kultura klanu (z wyjątkiem badanych w wieku powyżej 55 lat, którzy jako równie pożądaną wskazali kulturę adhokracji oraz hierarchii). Bardzo interesująca jest zgodność opinii badanych respondentów. Cechy kultury klanu okazały się priorytetowe szczególnie dla pracowników w wieku 46-55 lat oraz młodszych, począwszy od osób w wieku 18-25 lat. Interesujące są również opinie dotyczące pozostałych modeli kultur. Kultura hierarchii, jako model pożądany, zyskała najwięcej zwolenników wśród osób w wieku 26-35 lat, zdecydowanie najmniej natomiast w grupie respondentów w wieku 46-55 lat. 
Wskazania dotyczące modelu kultury adhokracji kształtowały się na poziomie 9-16\% oraz 33\% (osoby w wieku powyżej 55 lat). Najbardziej niepożądanym modelem kultury okazała się, zgodnie z wynikami zaprezentowanymi na Rysunku 3, kultura rynku. Jako model pożądany wskazało ją zaledwie $6 \%$ badanych w wieku 18-25 lat, 8\% w wieku 26-35 lat, 10\% w wieku 36-45 lat, 7\% w wieku 46-55 lat. Osoby w wieku powyżej 55 lat nie wskazały tego modelu w ogóle.

Wyniki badań w wyraźny sposób udowodniły, iż najwyżej cenionymi przez współczesnych pracowników, co bardzo istotne - w każdym wieku, są: przyjazne relacje międzyludzkie, wysoki poziom wzajemnego zaufania, wsparcie ze strony przełożonych oraz kolegów, praca zespołowa, możliwość partycypacji w procesie zarządzania, lojalność, swobodne artykułowanie swoich emocji w bezpiecznym środowisku pracy, czyli cechy typowe dla kultury klanu. Niestety, w badanych organizacjach dominującym modelem kultury okazała się kultura rynku z charakterystycznymi dla niej wartościami: konkurencyjnością oraz wynikami „za wszelką cenę". Przypuszcza się, że pracownicy zatrudnieni w organizacjach o tym typie kultury mogą świadomie, aczkolwiek wbrew sobie, redukować swoje rzeczywiste potrzeby bądź nie mówić o nich otwarcie w obawie przed negatywnymi konsekwencjami (Reis, Trulen, Story, 2016: 1093). Jednak czy będą wtedy w pełni identyfikowali się z organizacją? Czy będą z ochotą przychodzili do pracy, będą zmotywowani do niej, pełni zaangażowania, bez poczucia stresu? Bardzo wątpliwe.

\section{Podsumowanie}

Celem niniejszego artykułu było zaprezentowanie autorskich wyników badań mających na celu identyfikację obecnego oraz pożądanego modelu kultury organizacyjnej w ocenie wybranej grupy respondentów oraz sprawdzenie, czy ich wiek stanowi czynnik różnicujący opinie dotyczące powyższych kwestii. Analiza zebranego materiału faktograficznego pozwoliła znaleźć odpowiedź na sformułowane pytania badawcze i przedstawić następujące wnioski końcowe:

1. Dominującymi modelami kultury organizacyjnej, wskazanymi jako modele obecnie istniejące, są: kultura hierarchii (30,2\% wskazań) oraz kultura rynku (29,1\%).

2. Modelem najbardziej pożądanym przez respondentów okazał się model kultury klanu (40,1\%), a najmniej pożądanym model kultury rynku $(16,8 \%)$.

3. Model kultury organizacyjnej, deklarowany przez respondentów jako obecnie istniejący, wyraźnie odbiega więc od modelu pożądanego.

4. Zależność między modelem kultury organizacyjnej, deklarowanym jako pożądany przez respondentów, a ich wiekiem nie jest istotna statystycznie.

5. Modelem kultury organizacyjnej najczęściej wskazywanym jako pożądany przez przedstawicieli wszystkich grup wiekowych okazała się kultura klanu, najrzadziej zaś kultura rynku. 
Otrzymane wyniki badań sugerują, iż jednoznaczne przypisywanie pewnych cech oraz wskazywanie z góry przyjętych preferencji pracownikom należącym do tych samych grup pokoleniowych wydaje się nieuprawnione. Uczestnicy prezentowanych badań, zróżnicowani wiekowo, wskazali jako szczególnie pożądany ten sam typ modelu kultury organizacyjnej - kulturę klanu. Podobnie zgodni byli, wskazując model przez nich szczególnie niepożądany - kulturę rynku. Wiek nie okazał się więc kategorią różnicującą. Podobne w swojej wymowie spostrzeżenia prezentują także inni autorzy, na przykład M. Brol (2016: 46). Badania, na które się powołuje, miały na celu pozyskanie od respondentów University of Wisconsin - Eau Claire opinii dotyczących tego, w jakim stopniu poszczególne generacje uważają, że są różne i w jakim stopniu faktycznie się różnią. Pracowników podzielono na trzy generacje, ich ocenie poddano 15 aspektów, które mogą być ważne w kontekście ich pracy, na przykład: pracę zespołową (teamwork), autonomię (autonomy), bezpieczeństwo (security), profesjonalizm (professionalism), elastyczność (flexibility), formalną władzę (formal authority), technologię (technology) itd. Ich zadanie było dwojakiego rodzaju. Z jednej strony musieli dokonać oceny, odnosząc ją do siebie, a drugiej do przedstawicieli innych pokoleń. W omawianych badaniach potwierdzono jedynie częściowe istnienie faktycznych różnic w wartościowaniu 15 elementów przez przedstawicieli poszczególnych kategorii pokoleniowych. Dodatkowo wyniki ujawniły, że różnice międzypokoleniowe postrzegane przez badanych znacznie przewyższają te, które wynikają z podanych przez nich wartości (Lester, Standifer, Schultz, Windsor, 2012: 347). Na brak istotnych różnic w aspekcie multigeneracyjności zwraca uwagę także M. Brown (2012: 3592) twierdząc, iż: „Aktualne badania wskazują, że nie ma istotnych różnic w postawach pracy pośród różnych pokoleń".

Dokonując próby ostatecznej konkluzji, należy stwierdzić, iż bardzo często nasza wiedza opiera się wyłącznie na poszlakach i opiniach formułowanych na podstawie stereotypowego postrzegania rzeczywistości. Tymczasem warto dysponować prawdziwą i aktualną wiedzą na temat rzeczywistych oczekiwań, preferencji, wartości kluczowych dla pracowników zatrudnionych na wszystkich szczeblach hierarchii organizacyjnej, warto też o nich otwarcie rozmawiać, by nie opierać się na domysłach, które często mogą być mylące.

Zaprezentowane $w$ niniejszym artykule wyniki badań oparte zostały na opiniach respondentów z jednego z polskich województw - studentów uczelni ekonomicznych. $Z$ pewnością może to stanowić pewnego rodzaju ograniczenie. Godne uwagi byłoby poszerzenie zakresu badań i większa dywersyfikacja respondentów, na przykład włączenie do grona badanych także reprezentantów innych specjalności oraz osób zamieszkujących i pracujących w innych regionach Polski lub za granicą. Zależność między wiekiem pracownika i jego odmiennością kulturową (najlepiej w skali globalnej) a preferencjami dotyczącymi modelu kultury organizacyjnej może stanowić przedmiot dalszej, jakże interesującej eksploracji naukowej. 


\section{Bibliografia}

Altaf A. (2011), The impact of organizational culture on organizational effectiveness: implication of Hofstede Cultural Model as organizational effectiveness model, „The International Journal of Interdisciplinary Social Sciences", t. 6, cz. 1, s. 161-162.

Aniszewska G. (red.) (2007), Kultura organizacyjna w zarządzaniu, Polskie Wydawnictwo Ekonomiczne, Warszawa.

Aybas M., Cevat Acar A. (2017), The Effect of Human Resource Management Practices on Employees' Work Engagement and the Mediating and Moderating Role of Positive Psychological Capital, „International Review of Management and Marketing”, t. 7, nr 1, s. 363-372.

Bennett M.M., Beehr T.A., Ivanitskaya L.V. (2017), Work-family conflict: differences across generations and life cycles, „Journal of Managerial Psychology”, t. 32, nr 4, s. 314-332.

Brol M. (2016), Różnice pokoleń na rynku pracy? Nowe spojrzenie na znane zjawisko, „Społeczeństwo i Edukacja”, t. 21, nr 2, s. 41-49.

Brown M. (2012), Responses to work intensification: does generation matter?, „The International Journal of Human Resource Management”, nr 23(17), s. 3578-3595.

Cameron K.S., Quinn R.E. (2003), Kultura organizacyjna - diagnoza i zmiana, Oficyna Ekonomiczna, Kraków.

Connolly L.Y., Lang M., Gathegi J., Tygar D. J. (2017), Organisational culture, procedural countermeasures, and employee security behavior. A qualitative study, ,Information \& Computer Security", t. 25, nr 2, s. 118-136, http://doi.org/10.1108/ICS-03-2017-0013.

Costanza D.P., Badger J.M., Fraser R.L., Severt J.B., Gade P.A. (2012), Generational Differences in Work-Related Attitudes: A Meta-analysis, ,Journal of Business and Psychology”, t. 27, s. 375-394, http://doi.org/10.1007/s10869-012-9259-4.

Cucina J.M., Byle K.A., Martin N.R., Gast I.F. (2017), Generational differences in workplace attitudes and job satisfaction, ,Journal of Managerial Psychology”, t. 33, nr 3, s. 246-264.

Douglas J., Muturi D., Douglas A., Ochieng J. (2017), The role of organisational climate in readiness for change to Lean Six Sigma, „The TQM Journal”, t. 29, nr 5, s. 666-676.

Eaton D., Kilby G. (2015), Does your organisational culture suppert your business strategy?, „The Journal for Quality \& Participation", nr 1, s. 4-7.

Gimenez-Espin J.A., Jiménez-Jiménez D., Martínez-Costa M. (2013), Organizational culture for total quality management, „Total Quality Management”, t. 24, nr 6, s. 678-692.

Guillot-Soulez Ch., Soulez S. (2014), On the heterogeneity of Generation Y job preferences, „Employee Relations", t. 36, nr 4, s. 319-332.

Harrington H. J., Voehl F. (2015), Cultural Change Management, „International Journal of Innovation Science", t. 7, nr 1, s. 55-74.

Hoole C., Bonnema J. (2015), Work engagement and meaningful work across generational cohort, „South African Journal of Human Resource Management”, t. 13, nr 1, s. 1-11, https://doi. org/10.4102/sajhrm.v13i1.681.

Hulkko-Nyman K., Sarti D., Hakonen A., Sweins C. (2014), Total rewards perceptions and work engagement in elder-care organizations: Findings from Finland and Italy, „International Studies of Management \& Organization”, t. 42, nr 1, s. 24-49, https://doi.org/10.2753/ IMO0020-8825420102.

Jacobs S., Renard M., Snelgar R.J. (2014), Intrinsic rewards and work engagement in the South African retail industry, „South African Journal of Industrial Psychology”, t. 40, nr 2, s. 1-13, https://sajip.co.za/index.php/sajip/article/view/1195/1652 [dostęp: 15.10.2018].

Kokt D., Ramarumo R. (2014), Impact of organisational culture on job stress and burnout in graded accommodation establishments in the Free State province, South Africa, „International Journal of Contemporary Hospitality Management”, t. 27, nr 6, s. 1198-1213. 
Kovačić Z.J. (2005), The impact of national culture on worldwide e-Government readiness, „Informing Science Journal", t. 8, s. 143-158.

Krzyworzeka P. (2012), Kultura organizacji-ślepa uliczka teorii organizacji, „Management and Business Administration. Central Europe", nr 1(108), s. 72-81.

La Montagne R.M. (2016), Ethical dilemmas in the workplace: HR managers' perceptions of behavioral influences with implications for building an ethical culture in organizations, „The International Journal of Knowledge, Culture, and Change Management: Annual Review", t. 15, s. 9-21.

Laforet S. (2015), Effects of organisational culture on organisational innovation performance in family firms, ,Journal of Small Business and Enterprise Development”, t. 23, nr 2, s. 379-407.

Lester S.W., Standifer R.L., Schultz N.J., Windsor J.M. (2012), Actual versus perceived generational differences at work an empirical examination, ,Journal of Leadership \& Organizational Studies", nr 19(3), s. 341-354.

Levickaite R. (2010), Generations X, Y, Z: how social networks form the concept of the world without borders (the case of Lithuania), „Limes”, t. 3, nr 2, s. 170-183.

Markiewicz P. (2005), Kultura organizacyjna jako determinanta wyboru strategii konkurencji, „Zeszyty Naukowe Akademii Ekonomicznej w Krakowie”, nr 673, s. 39-53.

Neagu E. R., Nicula V. (2012), Influence of organizational culture on company performance, „Management and Economics", nr 4(68), s. 420-424.

Pakdil F., Leonard K.M. (2014), The effect of organizational culture on implementing and sustaining lean processes, „Journal of Manufacturing Technology Management”, t. 26, nr 5, s. 725-743.

Pietruszka-Ortyl A. (2016), Dysfunkcje i patologie kultury organizacyjnej w perspektywie Polski, „Nierówności Społeczne a Wzrost Gospodarczy”, nr 46(2), s. 438-448.

Reis G., Trullen J., Story J. (2016), Perceived organizational culture and engagement: the mediating role of authenticity, „Journal of Managerial Psychology”, t. 31, nr 6, s. 1091-1105.

Rich B.L., Lepine J.A., Crawford J.R. (2010), Job engagement: Antecedents and effects on job performance, ,Academy of Management Journal”, t. 53, nr 3, s. 617-635, https://doi.org/10.5465/ AMJ.2010.51468988.

Rodrigues J.K., Stewart P. (2017), HRM and work practices in Chile: the regulatory power of organisational culture, „Employee Relations”, t. 39, nr 3, s. 378-390.

Saad R., Asaad M.N. (2015), Does organizational culture moderate the relationship between ISO 9000 soft factors and organizational performance?, „The Journal of Developing Areas”, t. 49 , nr 3, s. 379-394.

Sarraf A.R., Abzari M., Isfahani A.N., Fathi S. (2017), Generational differences in job engagement: a case study of an industrial organization in Iran, „Industrial and Commercial Training", t. 49, nr 3, s. 106-115.

Serafin K. (2015), Kultura organizacyjna jako element wspierający realizację strategii przedsiębiorstwa, „Studia Ekonomiczne. Zaszyty Naukowe Uniwersytetu Ekonomicznego w Katowicach", nr 222, s. 87-100.

Shragay D., Tziner A. (2011), The Generational Effect on the Relationship between Job Involvement, Work Satisfaction, and Organizational Citizenship Behavior, „Revista de Psicología del Trabajo y de las Organizaciones", t. 27, nr 2, s. 143-157.

Smolbik-Jęczmień A. (2013), Rozwój kariery zawodowej przedstawicieli pokolenia X $i$ Y w warunkach gospodarki opartej na wiedzy, „Nierówności Społeczne a Wzrost Gospodarczy”, nr 36, s. 228-238.

Sokro E. (2012), Analysis of the relationship that exists between organisational culture, motivation and performance, „Problems of Management in the $21^{\text {th }}$ Century”, t. 12, s. 106-119.

Srokowski Ł. (2011), Zmienić myślenie o firmie. Zarzadzanie kultura organizacyjna w Polsce, Poltext, Warszawa. 
Su Z., Yang D., Yang J. (2012), The match between efficiency/flexibility strategy and organisational culture, „International Journal of Production Research”, t. 50, nr 19, s. 5317-5329.

Sułkowski Ł. (2011), Krytyczna wizja kultury organizacyjnej, „Problemy Zarządzania”, t. 9, nr 4(34), s. $7-25$.

Szukalski P. (2012), Solidarność pokoleń. Dylematy relacji międzypokoleniowych, Wydawnictwo Uniwersytetu Łódzkiego, Łódź.

Tarnowska A. (2011), Mobbing - patologia kultury organizacyjnej, „Studia i Materiały. Miscellanea Oeconomicae”, Wydział Zarządzania i Administracji Uniwersytetu Jana Kochanowskiego w Kielcach, nr 2, s. 73-81.

Tepeci M. (2011), The impact of person-organization fit on employee attitudes in the hospitality industry, ,Journal of Travel and Tourism Research”, t. 11, nr 1, s. 19-35.

Tolentino R.C. (2013), Organizational Commitment and Job Performance of the Academic and Administrative Personnel, „International Journal of Information Technology and Business Management", t. 15, nr 1, s. 51-59.

Victor J., Hoole C. (2017), The influence of organisational rewards on workplace trust and work engagement, „SA Journal of Human Resource Management”, t. 15, s. 1-14, https://doi. org/10.4102/sajhrm.v15i0.853.

Waal A., Peters L. Broekhuizen M. (2016), Do different generations look differently at high performance organizations?, „Journal of Strategy and Management”, t. 10, nr 1, s. 86-101.

Weare Ch., Lichterman P., Esparza N. (2014), Collaboration and Culture: Organizational Culture and the Dynamics of Collaborative Policy Networks, „The Policy Studies Journal”, t. 42, nr 4, s. 590-619.

Westerman J.W., Yamamura J.H. (2006), Generational preferences for work environment fit: effects on employee outcomes, „Career Development International”, t. 12, nr 2, s. 150-161.

Wong M., Gardiner E., Lang W., Coulon L. (2008), Generational differences in personality and motivation, „Journal of Managerial Psychology”, t. 23, nr 8, s. 878-890.

Wudarzewski G. (2013), Wymiary i składniki klimatu organizacyjnego w świetle badań literaturowych, „Zeszyty Naukowe Wyższej Szkoły Bankowej we Wrocławiu”, nr 1(33), s. 59-78.

Wziątek-Staśko A. (2012), Diversity Management-narzędzie skutecznego motywowania pracowników, Difin, Warszawa.

Wziątek-Staśko A. (2015), Wiek kluczowym wyróżnikiem różnorodności pracowników-implikacje dla motywowania, „Społeczeństwo i Edukacja”, t. 16, nr 1, s. 47-60.

Wziątek-Staśko A. (2017), Model kultury organizacyjnej a zjawiska patologiczne w środowisku pracy, „Przegląd Organizacji”, nr 10, s. 27-34.

Wziątek-Staśko A. (2018), Kulturowe uwarunkowania poziomu motywacji i zaangażowania pracowników, „Marketing i Zarządzanie”, nr 1(51), s. 409-419, http://doi.org/10.18276/miz.2018.51-39.

Wziątek-Staśko A., Krawczyk-Antoniuk O. (2017), Pozytywny klimat w organizacji czynnikiem determinującym poczucie satysfakcji z pracy, „Marketing i Rynek”, nr 4, s. 185-193.

Yiing L.H., Ahmad K., Bin Z. (2009), The moderating effects of organizational culture on the relationships between leadership behaviour and organizational commitment and between organizational commitment and job satisfaction and performance, „Leadership \& Organization Development Journal", t. 30, nr 1, s. 53-89.

Yongxing G., Hongfei D., Baoguo X., Lei M. (2017), Work engagement and job performance: the moderating role of perceived organizational support, „Anales de Psicología”, t. 33, nr 3 (October), s. 708-713, http://dx.doi.org/10.6018/analesps.33.3.238571.

Zbiegień-Maciąg L. (1999), Kultura w organizacji. Identyfikacja kultury znanych firm, Wydawnictwo Naukowe PWN, Warszawa.

Zheng W., Wu Y.-Ch.J., Chen X., Lin S. (2017), Why do employees have counterproductive work behavior? The role of founder's Machiavellianism and the corporate culture in China, „Management Decision", t. 55, nr 3, s. 563-578. 


\title{
Generational Diversity of Employees and the Preferred Organizational Culture Model
}

\begin{abstract}
The convergence of key values for an organization with values relevant to employees is a research problem of high priority for modern entrepreneurs and one of the key challenges that they should devote special attention to. The subject of considerations taken in this article is the organizational culture and its perception by employees of different ages. The increasingly visible stereotyping of features and preferences of representatives of different generations, regarding their functioning in the work environment, has become an inspiration to undertake original research in this area. The participants of the research were 664 Polish respondents. The quantitative methods were used in the research process. The purpose of the article is to present the current and desired organizational culture model in the assessment of employees at different ages.
\end{abstract}

Keywords: organizational culture, model, age, generation

JEL: M12, M54, M55

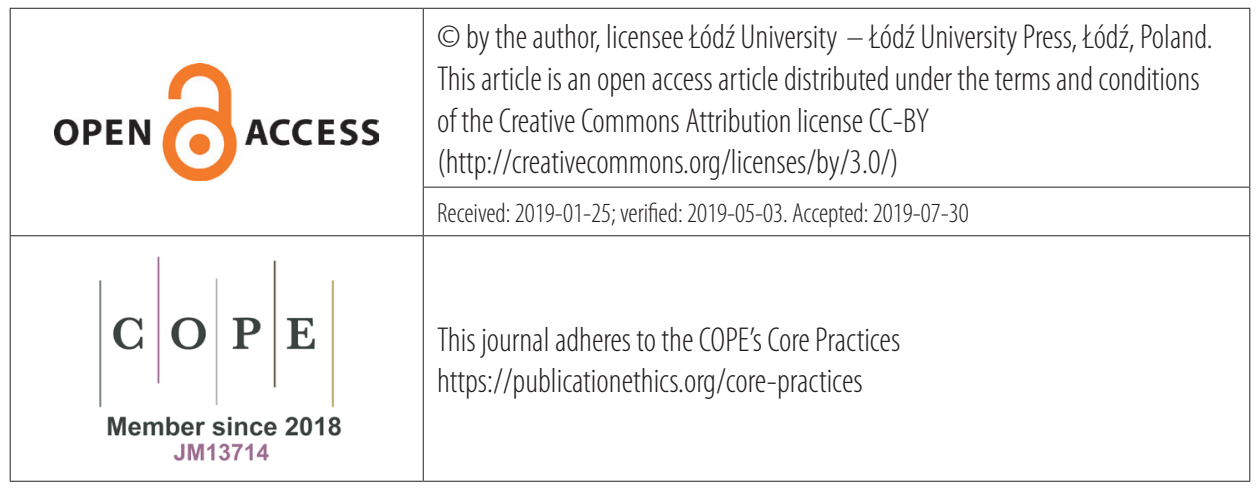

